\title{
As consequências da BR 158/MT para o território indígena de Marãiwatsédé
}

\author{
Eliseu Demambro ${ }^{1}$ \\ Pedro Araújo Pietrafesa ${ }^{2}$ \\ Gabriela Vivian Gómez Rojas ${ }^{3}$
}

\begin{abstract}
Resumo
O presente artigo analisa as consequências da rodovia BR 158/MT para a comunidade indígena do povo Xavante que vivia na área chamada Marãiwatsédé ao leste do Estado de Mato Grosso e sofreram com processos de remoção e expropriação de seu território. Este conflito iniciou na década de 1960 e expõe o protagonismo deste povo durante o processo de luta pela terra e retorno ao território já no ano de 2013. A metodologia utilizada, de cunho qualitativo, ancorar-se-á em pesquisa bibliográfico-documental e pesquisa de campo, por meio de entrevista não estruturada. Desta forma, o artigo apresenta as percepções de lideranças indígenas a respeito da rodovia que ora passava dentro de seu território e agora faz um contorno na mesma área. Com a intenção de atender as metas do governo federal, o estado de Mato Grosso priorizou o desenvolvimento econômico e as comunidades indígenas sofreram grandes perdas de seu território original. Um dos resultados deste artigo foi que mesmo achando a BR 158/MT extremamente necessária para sua sobrevivência, os líderes indígenas se queixam da não participação nas discussões que definem ações dentro de seus territórios.
\end{abstract}

Palavras Chaves: BR 158 MT; Marãiwatsédé; Xavante.

\begin{abstract}
The article analyzes the consequences of the BR 158/MT road for the indigenous community of the Xavante people who lived in the area called Maraniwatsédé in the eastern region of Mato Grosso and suffered from processes of removal and expropriation of their territory. This conflict started in the 1960s and exposes the protagonism of this people during the fighting for land and returning to the territory in 2013. The applied methodology, of qualitative quality, anchored in bibliographic, documentary and field research, through unstructured interviews. In this way, the article presents perceptions of indigenous leaders regarding the highway that now passes within their territory and now makes an outline in the same area. With the intention of meeting the goals of the federal government, the state of Mato Grosso prioritized economic development and indigenous communities suffered great losses from their original territory. One of the results of this article was that even though the BR $158 M T$ was extremely necessary for its survival, indigenous leaders complain about not participating in the discussions that define actions within their territories.
\end{abstract}

Keywords: BR 158 MT. Marãiwatsédé. Xavante.

\footnotetext{
${ }^{1}$ Doutorando em Ciências Empresariais e Sociais (UCES-Argentina). Professor no Instituto Federal de Educação, Ciência e Tecnologia de Mato Grosso (IFMT), Campus Barra do Garças. elizeu14@hotmail.com

2 Doutor em Ciências Sociais (UnB). Professor no Programa de Pós-Graduação em Desenvolvimento e Planejamento Territorial da PUC de Goiás. https://orcid.org/0000-0003-0542-4753. pedro.pietrafesa@gmail.com

${ }^{3}$ Pos-doctora en Estudios de Género (UCES-Argentina). Doctora en Ciencias Sociales (Universidad de Buenos Aires). Professora na Universidade de Ciências Empresariais e Sociais (UCES-Argentina). gvgrojas@gmail.com
} 


\section{Introdução}

O estado de Mato Grosso está localizado no centro da América Latina e ocupa uma área de $903.366 .192 \mathrm{~km}^{2}$ do território brasileiro, fazendo parte da região Centro-Oeste do país. Sua população, segundo estimativa populacional de 2018, é de 3.441.998 habitantes, concentrando $1,6 \%$ da população brasileira, com uma densidade demográfica de 3,36 habitantes por quilômetro quadrado segundo estimativa IBGE 2018 (IBGE, 2019).

Dentro do Estado de Mato Grosso, a BR 158 possui 800 km, começando do km 0,0 (divisa com o Pará) indo até o quilometro 800,5, entroncamento com a BR 070 em Barra do Garças. A abertura da estrada começou, em 1940, pelo quilômetro 800,5 e terminou, em meados de 1980, já no quilometro 0,0 . Seu asfaltamento se deu na mesma trajetória, iniciando-se no município de Barra do Garças, em 1985, e chegando em Vila Rica (divisa com o Pará), em 2015 (GALVÃO, 2013).

A rodovia BR-158 foi idealizada, por volta de 1944, pelo presidente Getúlio Vargas (18821954), incluída no projeto de interiorização. Atravessando o Brasil, de norte a sul, teve sua implantação definitiva em 1970 e conecta-se à rodovia BR-230, no município de Altamira (PA), percorrendo $3.964 \mathrm{~km}$ até o município de Santana do Livramento (RS), fronteira com o Uruguai, passando pelos estados de Mato Grosso, Goiás, Mato Grosso do Sul, São Paulo, Paraná e Santa Catarina (GALVÃO, 2013).

Existe um trecho da BR-158 que ainda não tem licença para asfaltamento, trata-se de um trecho de aproximadamente 210 km, que contorna as terras indígenas de Marãiwatsédé ("mata fechada" na língua indígena), que está sob análise do DNIT (Departamento Nacional de Infraestrutura e Transportes) para a pavimentação, neste ponto a estrada sofre um desvio, contornando essas terras, objeto de conflito entre índios, posseiros e fazendeiros da região.

Na única aldeia da Terra Indígena Marãiwatsédé localizada no divisor das águas das bacias do Araguaia e do Xingu, no nordeste do Mato Grosso, vivem cerca de 1.130 indígenas em 83 casas dispostas em forma de semicírculo. Há também, uma igreja, um posto de saúde, uma casa assistencial, uma escola e uma casa da ONG Operação Amazônia Nativa (Opan), todas fora do semicírculo. Em 165 mil hectares da TI (Terras Indígenas) Marãiwatsédé os indígenas plantam arroz, mandioca, milho tradicional, feijão xavante e frutas e, ainda em fase incipiente, estão pastoreando gado (REDE BRASIL ATUAL, 2014). Porém, para chegarem a essa situação, passaram por um processo de remoção e desintrusão de seu território. 
O objetivo desse artigo é analisar as consequências, como a desterritorização e a violência, que obras de infraestrutura como a BR 158 MT e o avanço do agronegócio, causaram na região demarcada da Terra Indígena Marãiwatsédé. A metodologia utilizada, de cunho qualitativo, ancorar-se-á em pesquisa bibliográfico-documental e pesquisa de campo, por meio de entrevista não estruturada. A pesquisa qualitativa se preocupa com o aprofundamento da compreensão de um grupo social (GOLDENBERG,1997, p.34).

O artigo está dividido em seis seções. A que segue esta introdução aborda o histórico da construção da BR 158/MT. A Terceira seção trata da expulsão do povo Xavante da região de Marãiwatsédé. A quarta seção, por sua vez, analisa o retorno, quase quarenta anos depois, da população indígena as terras das quais foram expulsos. A quinta seção, aborda a percepção indígena da rodovia BR 158 para a comunidade tradicional. E por último, é apresentada a conclusão do trabalho.

\section{A história da construção da BR 158}

A criação, em 1937, do Departamento Nacional de Estradas de Rodagem (DNER) indicou que o governo Getúlio Vargas daria destaque para a construção de infraestrutura rodoviária no projeto governamental de modernização econômica do país. Com o fim do governo de Getúlio Vargas (1954) e o início do governo Juscelino Kubitschek (1956), foram mantidas as linhas de políticas de povoamento, de transporte e de comunicação, culminando com a construção de Brasília, que mostrou uma nova "Marcha para o Oeste". "Levando o poder central para o interior, iniciando um processo de deslocamento da modernização, até então somente encontrada na região Centro-Sul, para a região Centro-Oeste" (OLIVEIRA, 2015).

Em 1962, o Plano Nacional de Viação (PNV) denominou o itinerário da rodovia chamada atualmente de BR 158, entre Barra do Garças e o rio das Mortes, como BR-72. Quatro anos depois, a sigla rodoviária BR-72, embora com seu traçado original um pouco alterado, é mudada para BR-158/MT, que, juntando com os trechos citados anteriormente chegava até a cidade de Santana do Araguaia, no Pará. Somente em 1970 é que o DNER assume o traçado preconizado pela MTT-158, como BR-158/MT (SR/DNIT/MT, 2015).

Na pavimentação dos 800 quilômetros da BR 158, dentro do estado do Mato Grosso, existe uma evolução cronológica que começa no km 0,0 (divisa com o Pará) e vai até o km 275,5 (Br-242) no rio Liberdade, onde sua implantação terrosa foi feita dos idos de 1975 até meados 
de 1980, com a denominação de rodovia Estadual Transitória, sigla MTT-158, e essa implantação foi efetivada com recursos do governo de Mato Grosso e da Superintendência do Desenvolvimento do Centro-Oeste (SUDECO ${ }^{1}$ ). A SUDECO construiu também o segmento do km 275,5 até o km 337,0 (município de Alô Brasil), em 1968, chegando a atingir a cidade de São Félix do Araguaia, distante $115 \mathrm{~km}$ pela rodovia BR-242/MT, conservada pela mesma Superintendência, até 1972 (DNIT, 2019).

O trecho compreendido entre o km 337,0 (município de Alô Brasil) e o km 517,5 (entroncamento para o município de Canarana) foi feito no período entre 1966 e 1967, pela Fundação Brasil Central, que também executou a implantação terrosa nos quilômetros 517,5 ao 657,7 (município de Nova Xavantina), mas esta foi feita no ano de 1965. Em relação aos quilômetros restantes, de 657,7 até o quilômetro 800,5 , entroncamento com a BR 070, no município de Barra do Garças, a construção se deu entre os anos 1940-1944 (DNIT, 2019).

Ao observarmos o Quadro 1 podemos notar que o asfaltamento total da BR 158 MT levou trinta anos e ainda existe um trecho da BR-158 que ainda não tem licença para asfaltamento, entre os municípios de Ribeirão Cascalheira e Porto Alegre do Norte, que corta a terra indígena Marãiwatsédé; neste ponto a estrada sofre um desvio de mais 210 quilômetros, contornando essas terras, objeto de conflito entre índios, posseiros e fazendeiros da região. O Quadro 1 demonstra como se deu o revestimento asfáltico da BR 158/MT, em ordem cronológica.

Quadro 1- Etapas de construção da rodovia BR 158/MT (1985 a 2015)

\begin{tabular}{|l|l|}
\hline Anos & \multicolumn{1}{|c|}{ Asfaltamento } \\
\hline 1985 a 1987 & Km 514,8 (trevo de Canarana) até Barra do Garças. \\
\hline 1999 a 2001 & Km 412,2 (Ribeirão Cascalheira) até Km 514,8 - (faltavam 17 km de asfalto neste trecho) \\
\hline 2004 a 2005 & Foram concluídos os 17 km faltantes de asfalto do trecho acima. \\
\hline 2009 a 2013 & Km 327.5 (Alô Brasil) até 412,2. \\
\hline 2009 a 2011 & Km 135,0 (Confresa) até km 201,13. \\
\hline 2009 a 2014 & Km 69,14 (divisa entre Confresa e Vila Rica) até km 135,0. \\
\hline 2009 a 2015 & Km 0,00 (divisa PA/MT) até km 69,14. \\
\hline
\end{tabular}

Fonte: DNIT/MT (2015) Desenvolvido pelo engenheiro Otto Zittlau.

1 SUDECO - (Superintendência do Desenvolvimento do Centro-Oeste) tem finalidade de promover o desenvolvimento regional, de forma includente e sustentável, e a integração competitiva da base produtiva regional na economia nacional e internacional (SUDECO, 2016). 
A seguir vamos entender que o projeto desenvolvimentista do governo acabou por atingir os povos indígenas afastando-os de suas terras e iniciando um processo de migração forçada culminando em um desairragamento e perdas irreversíveis.

\section{Xavante: a expulsão de Marãiwatsédé}

No governo Vargas na década de 1930, o Brasil passou por um momento decisivo em sua história econômica e política, o governo altamente centralizador passa a reforçar o nacionalismo e a intervenção estatal na economia e na sociedade, enfatizando a necessidade em estimular o desenvolvimento e a integração nacional (WELCH ET AL. 2013, p. 33).

Nesta perspectiva, Vargas havia feito um projeto de ocupação territorial da região CentroOeste, que ficou conhecido como - Marcha para o Oeste, idealizado em 1938 (OLIVEIRA, 2016). Este projeto governamental tinha como objetivo povoar o interior do Brasil através do desenvolvimento humano e econômico. Sendo um projeto desenvolvimentista, teve um grande apoio do Estado que garantiu as condições necessárias de manter as populações nas regiões que iriam ocupando e ao mesmo tempo atraindo investimentos; assim o Estado se responsabilizava pela construção da infraestrutura necessária (OLIVEIRA, 2016).

Foi assim que a BR 158/MT passou a ser idealizada, com o avanço dessas frentes desenvolvimentistas na região do Médio Araguaia, foi-se formando povoados ao longo de seu trecho terroso, onde, posteriormente, se tornaram municípios do estado de Mato Grosso (OLIVEIRA, 2016). Com esse avanço para cumprir as metas do governo em sua estratégia desenvolvimentista na região do Médio Araguaia, estas frentes teriam um obstáculo a ser transpassado, as terras indígenas de Marãiwatsédé, onde viviam os índios da etnia Xavante (OLIVEIRA, 2016).

A BR 158 dentro do projeto do governo transpassava as terras indígenas de Marãiwatsédé e essas terras passaram a representar grande importância para a exploração comercial para muitos fazendeiros que por ali gostariam de se instalar, pois as terras indígenas eram inexploradas, férteis e com água em abundância, além de estar no caminho de uma grande rodovia que pode transportar toda a produção que essa terra gerar (OLIVEIRA, 2016). A figura1 mostra o local onde estão as terras de Marãiwatsédé no Estado de Mato Grosso. 
Figura 1: Território Marãiwatsédé

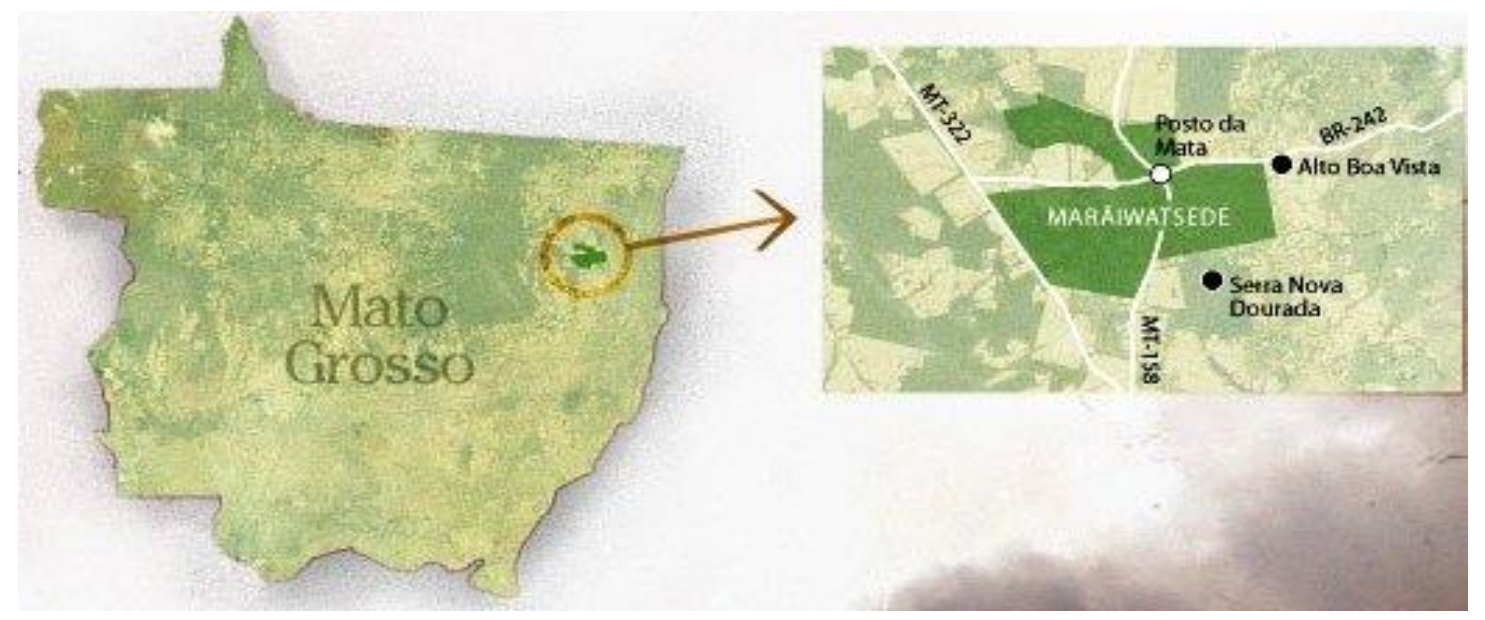

Fonte: Axa, 2014.

Marãiwatsédé possuía nascentes e terra fértil, desta maneira chamou a atenção de grandes fazendeiros, uma terra de boa qualidade e de grandes extensões é tudo que os fazendeiros precisam para iniciarem a agropecuária, primeiro derrubam as árvores e formam pastos e posteriormente entram com a agricultura (RODRIGUES, 1992 p. 24).

O governo federal conhecia a presença do povo Xavante em Marãiwatsédé e mesmo assim, na década de 1950 e 1960, a maior parte da área de seu território foi vendida pelo Estado de Mato Grosso. Vários documentos históricos oficiais indicam a presença dos povos indígenas nesta área, como por exemplo, um ofício enviado por Ismael da Silva Leitão, na ocasião funcionário público lotado no órgão SPI (Serviço de Proteção ao Índio), pedindo a criação de um PIA (Posto Indígena de Atração) com a finalidade de evitar a apropriação das terras por estrangeiros (RODRIGUES, 1992). A partir da década de 1950, começou a apropriação das terras pelos não índios, fato observado e descrito novamente ao diretor do SPI por Ismael Leitão onde explicou que as reservas de terras pertencentes aos povos Xavantes foram vendidas e foram distribuídos títulos de propriedade a inúmeros compradores aos quais estariam tomando posse (RODRIGUES, 1992 p. 24).

A expropriação do território dos Xavantes de Marãiwatsédé foi comprovada anos mais tarde por um laudo fundiário que levantou vinte e cinco títulos com até dez mil hectares comprados por diferentes titulares em 1960 do governo de Mato Grosso, e que posteriormente foram adquiridos por Ariosto da Riva proprietário da agropecuária Suiá Missú que já era proprietário de terras na região e assim somou e registrou como sua propriedade uma área total de 695.843.8551 hectares (ROSA e TAFNER, 2019). 
A primeira propriedade escriturada da região foi instalada em 1961 com grandes incentivos fiscais do governo federal, através de SUDAM (Superintendência de Desenvolvimento da Amazônia) a propriedade em questão era a fazenda Suiá Missú S/A em território Xavante tinha uma área de 695.843 hectares e $8351 \mathrm{~m}^{2}$, onde foi usado $\mathrm{Cr} \$ 4.427 .826,00$ de recursos próprios e $\operatorname{Cr} \$ 7.878 .000,00$ de recursos advindos do governo federal como forma de incentivos (CASALDALIGA, 1971, p.49).

Diversos incentivos foram concedidos pelo governo militar a família Ometto, que era proprietária da Fazenda Suiá Missú em sociedade com Ariosto da Riva, e, também, pretendiam usar mão-de-obra em situação degradante, ou seja, pessoas que trabalhassem em troca de alimentos. Assim, conseguiram atrair outras aldeias próximas da sede e se algum indígena demonstrasse resistência ao trabalho, era exterminado. Com isso convenceram duas aldeias da etnia Xavante a ficarem próximos e trabalharem para eles em troca de comida (DELUCI E PORTELA, 2013). Neste ponto é importante citar Garfield: "A fazenda oferecia comida e bugigangas aos índios em troca de prestação de serviços, como abertura de trilhas e construção de uma pista de pouso" (GARFIELD, 2011, p.163).

Com essa estrutura de trabalho, deu-se a pacificação com os índios, porém essa fase se esgotou em quatro anos e começaram os conflitos, pois os administradores da fazenda entendiam que a presença dos indígenas era onerosa e promíscua. Segundo Pérez Jáuregui:

\footnotetext{
"Para fortalecer a tendência a aceitar mudanças e conflitos como situações de aprendizagem e desenvolvimento, deve haver um fortalecimento da identidade de ambas as partes, com base na aceitação e tolerância diante das diferenças individuais, garantindo o direito à preservação da singularidade" (PÉREZ JÁUREGUI, 2016).
}

Então os proprietários da fazenda decidem removê-los para uma região próxima a cabeceira do Rio Xavantinho, uma área alagadiça, imprópria que não oferecia boas condições de mínima sobrevivência deixando-os expostos a fome e a doenças (GOMIDE, 2008). No ano de 1965, aconteceu o pior, morreram 11 indígenas da etnia Xavante, adultos e algo em torno de 20 crianças por conta de doenças e fome. Assim, os dirigentes da fazenda preocupados, convenceram, mais uma vez, os indígenas a mudar para outra região mais ao sul (GIACCARIA, 1990).

Os indígenas que representavam um incomodo para esses novos proprietários teriam como seu destino a Missão Salesiana de São Marcos, nas proximidades de Barra do Garças, onde já viviam alguns grupos de índios (ROCHA, 2018). A Missão Salesiana de São Marcos ficava a 
quatrocentos quilômetros da sede da fazenda e do território tradicional Xavante dentro do Estado de Mato Grosso. Os padres salesianos mantinham uma missão para atender a outro grupo, também Xavante e onde afirmavam existir muita caça e não haver mosquitos da malária (ROCHA, 2018).

Para que tudo parecesse "dentro da lei" os proprietários contaram com o apoio da FAB (força aérea brasileira), com os padres salesianos e com autorização do SPI (Serviço de Proteção ao Índio), então, em agosto de 1966, todos os 286 indígenas foram transportados em aviões da Força Aérea Brasileira em três viagens até a Missão Salesiana de São Marcos - MT (CANUTO, 2012). Segundo Damião Paridzané, índio Xavante que na época era criança, narrou da seguinte forma o episódio da transferência dos Xavantes:

\begin{abstract}
Os brancos pediram que viessem os aviões da Força Aérea Brasileira. Na hora do embarque eles nos cercaram como se fossemos bois. Eles nos empurraram prá dentro do avião sem o nosso consentimento. Essa terra era nossa e fomos arrancados daqui. Isso dói Maria. Não se brinca com isso. [...] Essa terra é sagrada, é nossa vida. Mesmo assim fomos tirados daqui como animais. Eles nos vigiavam prá que ninguém fugisse. Não tínhamos um minuto de paz. A vigília durava dia e noite. Foi assim que aconteceu (Damião Paridzané in VALE DOS ESQUECIDOS, 2010).
\end{abstract}

No relato do Padre Giaccaria, quando os Xavantes chegaram em São Marcos estavam muito debilitados e houve uma epidemia de sarampo e sem tratamento adequado e remédios foram falecendo, foram calculados cerca de 80 dos 286 que haviam sido removidos de Marãiwatsédé. Os Xavantes nunca tinham tido sarampo e todos pegaram, inclusive os que já habitavam São Marcos. Com a ideia fixa em retornar à Marãiwatsédé, os Xavantes não ficaram muito tempo em São Marcos e assim começaram a se deslocar para outros povoados indígenas em sentido à Marãiwatsédé (DELUCI E PORTELA, 2013).

O povo Xavante de Marãiwatsédé foi vítima de uma epidemia, e independente de números, marcou profundamente com lembranças dolorosas como relata Damião Paridzané: "Meus amigos de infância foram todos mortos. Não gosto nem de lembrar" (RODRIGUES, 1992, p. 65). As principais lembranças de sua infância foram marcadas pelo contato com o não índio, os deslocamentos em Marãiwatsédé, a remoção do seu povo para São Marcos e a epidemia de sarampo, são memórias traumáticas contadas por Damião Paridzané como sua versão histórica dos acontecimentos que marcaram a luta pela terra de Marãiwatsédé (POLLAK, 1989). Heidegger (1993) explica espacialidade para o ser humano como: 
O ser humano vivencia o espaço, ou seja, o espaço é fenômeno para o ser humano. Uma pessoa que seja muito importante para nós, pode parecer estar próxima, ainda que viva do outro lado do mundo. A casa na qual moro é determinada por este morar, não por suas dimensões (HEIDEGGER, 1993).

Após a epidemia os Xavantes de São Marcos se dispersaram em outras aldeias como a de Sangradouro, São José, Areões e Culuene em Mato Grosso. Já em 1967 parentes de Damião Paridzané mudaram para a Reserva Indígena Couto Magalhães, onde anos mais tarde, junto com outros guerreiros e anciões formou a aldeia Água Branca. Porém mesmo assim, os Xavantes se sentiam deslocados nessas terras (DELUCI E PORTELA, 2013).

Em 1980, quase houve um conflito entre os grupos Xavantes pelo motivo da morte de uma criança que não andava direito e caiu no rio, afogando-se. $O$ início desse conflito foi que o grupo Xavante Norõdzura, de Couto Magalhães, acusou o grupo de Marãiwatsédé de ter jogado a criança no rio, esse mesmo grupo Xavante Norõdzura não aceitava bem a presença do grupo Marãiwatsédé, achando que trouxeram má sorte a aldeia. Então, houve uma reunião entre os Xavantes Norõdzura com o grupo Xavante de Culuene para juntos lutarem contra os Xavantes de Marãiwatsédé que estavam em pequeno grupo. Para evitar um extermínio dos Marãiwatsédé, a FUNAI (Fundação Nacional do Índio) foi acionada para intervir no conflito, o presidente da FUNAI, na época, Cláudio Romero conseguiu evitar a tragédia, onde com alguns contatos feitos ao cacique Adão que vivia na aldeia de Areões surgiu um convite aos Xavantes de Marãiwatsédé para se mudarem para lá, e assim foi feito (DELUCI E PORTELA, 2013).

Ao chegarem à aldeia de Areões, os Xavantes de Marãiwatsédé perceberam que iriam passar anos difíceis, o terreno era formado por muita areia e cascalho, a mata era pequena e muito difícil de fazer uma roça, mesmo assim, construíram poucas casas para acomodar o povo de Marãiwatsédé, pois se tratava de pouca gente. Em Areões ficaram por três anos, na visão de Damião Paridzané lá se tornou um lugar escasso de recursos e produzia poucos alimentos, assim veio à decisão de mudança novamente, e em 1985 em uma reunião com o filho do cacique de Pimentel Barbosa, foi permitida a entrada do povo Marãiwatsédé nos limites da reserva indígena de Pimentel Barbosa. Então fundaram a aldeia de Água Branca que fica no extremo sul da reserva, onde por ali ficaram por quinze anos, em meados de 1993, mesmo em condições precárias o grupo aumentou para 300 pessoas originárias de Marãiwatsédé (FERRAZ E MAMPIERI, 1994).

A reserva de Pimentel Barbosa foi uma área recuperada pelos Xavantes dos não índios que vieram do sul do país e haviam colonizado aquela região na década de 1970, portanto o solo estava exaurido e havia escassez de recursos naturais (FERRAZ E MAMPIERI, 1994). 
A tranquilidade reinou naquela aldeia durante 15 anos, mas os Xavantes de Marãiwatsédé entendem que eram um povo banido e encontravam-se em "terras dos outros" e assim, associado com acusações de feitiçarias por Xavantes de outras aldeias próximas, se viram em mais uma situação de mudança. Então, Damião Paridzané, agora na condição de cacique, tomou a decisão de falar novamente com o presidente da FUNAI na época Cláudio Romero, para que juntos lutassem para o retorno do seu povo as terras de Marãiwatsédé. Houve o aceite do presidente da FUNAI para tentarem a demarcação das terras aos Xavantes (FERRAZ E MAMPIERI, 1994).

\section{0 retorno às terras de Marãiwatsédé}

O grupo Xavante de remanescentes de Marãiwatsédé juntamente com o apoio da FUNAI estava determinado a retornar para suas terras tradicionais, a partir de 1984 começam a articular a retomada de Marãiwatsédé, primeiro pleiteando uma indenização por perdas e danos em função da expropriação de suas terras em 1960. As primeiras tratativas na década de 1980 tiveram grande apoio do terceiro setor, ONGs nacionais e estrangeiras como também a opinião pública nacional e internacional, que naquele momento, tratavam de questões relacionadas ao meio ambiente da região amazônica e tinham acesso a notícias e problemas relacionados à Amazônia Legal (ROCHA, 2018 p. 126 e 127).

Uma ONG italiana chamada Campagna Nord-Sul (CNS), em 1990 divulgou uma pesquisa intitulada "Brasil Responsabilidades italianas na Amazônia" que apoiava a causa Xavante no processo de retorno em suas terras tradicionais. O estudo mostrava onde existiam grandes propriedades de terras de empresas italianas na Amazônia e, entre elas foi estudado o caso da Fazenda Suiá-Missú, que alguns anos anteriores havia sido adquirida pela empresa italiana Agip do Brasil S/A, com o nome de Liquifarm Agropecuária Suiá-Missú, assim foram feitos vários contatos com essa empresa na Itália por intermédio de sua subsidiária brasileira, a fim de verificar as decisões e os encaminhamentos da empresa em relação à fazenda Suiá-Missú e os índios Xavante, antes de submeter os resultados dos investimentos da Agip na região Amazônica à opinião pública (ROCHA, 2018 p. 126 e 127).

Em 1990 ainda foi apresentada e votada positivamente por unanimidade pelo parlamento italiano uma moção parlamentar da ratificação do acordo bilateral Itália-Brasil, para que o governo italiano se empenhasse na proteção dos ecossistemas amazônicos e na defesa dos 
direitos das populações indígenas com recursos do próprio governo da Itália (ROCHA, 2018 p. 129 e 130).

Com toda pressão da opinião pública durante a Conferência das Nações Unidas sobre o Meio Ambiente e Desenvolvimento, a Eco92 no Brasil, representantes da ONG CNS e representantes brasileiros juntamente com alguns Xavantes conversaram com o presidente da corporação italiana Agip Petroni e obtiveram o compromisso de restituição das terras de Marãiwatsédé onde a Liquifarm Agropecuária Suiá Missú S/A se encontrava (ROCHA, 2018 p. 129 e 130).

Após alguns contatos de representantes de ambos os lados a empresa Agip abriu as portas da Agropecuária Suiá Missú para que pesquisadores instituídos pela FUNAI fizessem um relatório de identificação da área indígena de Marãiwatsédé. Esse relatório foi acatado pela empresa Agip e assim culminou na delimitação de 200 mil hectares, onde 168 mil hectares eram incidentes na Liquefarm Agropecuária Suiá Missú e 32 fora de seus limites (ROCHA, 2018 p. 129 e 130).

A demarcação e homologação somente aconteceram em 11 de dezembro de 1998, e foram demarcados 165.241 hectares, por decreto do Presidente da República, Fernando Henrique Cardoso, então, dos 200 mil hectares apontados no estudo, somente entraram no decreto presidencial 165 mil, isso aconteceu por uma decisão tomada entre os dirigentes da FUNAI e governo que alegaram que dessa maneira iriam conseguir "apressar o processo" deixando o restante "pra depois" (DELUCI E PORTELA, 2013). A demora acabou permitindo que Marãiwatsédé fosse novamente invadida, agora por posseiros e grileiros, incentivados por políticos e fazendeiros da região (DELUCI E PORTELA, 2013).

Com essa invasão ocorrida após a homologação da demarcação das terras indígenas começou uma nova batalha de liminares judiciais para decidir sobre o direito ou não dos invasores permanecerem nas terras. Os invasores eram fazendeiros e posseiros que construíram estabelecimentos comerciais, criação de gado, plantação de soja, venda de lotes entre outros ocupantes e tinham conivência de governos estaduais e municipais, e assim, os indígenas que ali viviam tornavam-se forasteiros que estavam sob constante ameaça (DELUCI E PORTELA, 2013).

Os Xavantes cansados de esperar uma decisão judicial mais efetiva, promoveram uma tentativa de ocupação forçada nas terras de Marãiwatsédé. Porém essa tentativa foi totalmente reprimida pelos posseiros que fortemente armados, expulsaram os Xavante que ficaram acampados à beira da BR 158 (ROCHA, 2018 p.147). 
Os posseiros bem articulados com políticos regionais, sindicatos e advogados, buscaram uma solução junto ao governo Estadual aprovaram a lei no 9.564/11 que propunha uma permuta de áreas entre a União e o Estado de Mato Grosso, essa permuta era a troca de das terras de Marãiwatsédé pelo Parque Estadual do Araguaia. Os Xavante através de seus representantes logo contestaram essa manobra alegando que a própria constituição proíbe essa troca, desrespeita o artigo 231 da Constituição Federal de 1988 que reconhece os "[...] direitos originários sobre as terras que tradicionalmente ocupam, competindo à União demarcá-las, proteger e fazer respeitar todos os seus bens" e assim, a Procuradoria da República acatou a reinvindicação dos Xavante (ROCHA, 2018 p.156).

Em 2012 no mesmo período que tramitava essa manobra de permuta de terras, ocorreu na cidade do Rio de Janeiro a Conferência das Nações Unidas sobre Desenvolvimento Sustentável (Rio+20). Aproveitando essa oportunidade de visibilidade mundial, os Xavantes mais uma vez tiveram seu espaço na conferência para expor às suas reivindicações e condições que viviam e entregaram uma carta à presidente da República solicitando providências (THAFNER JR. E SILVA, 2015).

Em julho de 2012 foi apresentado ao Tribunal Regional Federal, um plano de desintrusão das terras de Marãiwatsédé e por considerarem que apresentava elementos coerentes com uma ação pacífica, os juízes deram parecer favorável. Assim, em novembro do mesmo ano, foram enviadas as primeiras notificações às famílias de não indígenas para desocuparem a área (DELUCl E PORTELA, 2013). Depois de tantos constrangimentos de ambos os lados dos posseiros e principalmente dos Xavantes que eram constantemente hostilizados o processo de desintrusão foi completado em 2013 (ROCHA, 2018 p.159).

Com o fim desse processo de retirada dos posseiros, os indígenas puderam retomar suas terras e assim enfrentarem mais um desafio que era povoar e reestruturar toda uma terra que foi devastada pelo agronegócio e recriar um novo cenário naquelas terras que outrora foram à morada de seus ancestrais (ROCHA, 2018 p.159). A seguir serão apresentadas algumas entrevistas realizadas com lideranças indígenas da região onde falam sobre a importância e problemas da rodovia BR158 MT para suas comunidades em um período mais recente. 


\section{A BR 158/MT na visão das entidades de apoio aos indígenas e as consequências}

Em entrevista concedida ao pesquisador o chefe local da FUNAI no município de Água Boa - MT que é um Xavante relatou suas preocupações em relação à BR 158. Sobre a BR 158, disse que na época de sua concepção não houve discussões com os indígenas, porém não é a favor de sua retirada, pelo contrário, quer, sim, uma melhora, pedindo acostamento e melhor sinalização, porque há constantemente mortes de indígenas e muitos animais silvestres, que são a base alimentar dessa população nas aldeias próximas (DEMAMBRO, 2017 p. 87).

No município de Confresa - MT foi entrevistado um indígena da etnia Tapirapé, coordenador da Fundação nacional da saúde/Secretaria de saúde indígena (FUNASA/SESAI), que fez algumas considerações; reclamou que as grandes rodovias trouxeram as plantações de soja nas divisas das terras indígenas e, com isso, chegou-lhes muita poluição, vez que os agrotóxicos lançados nas plantações de soja envenenaram animais e as águas. Também por seu povo estar próximo à rodovia, sofre muito com acidentes e a saúde indígena ficou muito prejudicada pelo fácil acesso à alimentação dos não índios, trazendo doenças, como diabetes e hipertensão.

O que a rodovia trouxe de bom foi que os indígenas se aproximaram dos municípios onde tem atendimento melhor para a saúde e a educação de seu povo (DEMAMBRO, 2017 p. 97). Na FUNAI de Barra do Garças - MT, o assistente da regional, em entrevista, primeiramente, falou que a BR 158 para os povos indígenas tem seu lado bom, uma vez que aproximou o governo federal para prestar mais assistência a eles, no que diz respeito à formação educacional e, principalmente, na área da saúde.

Mas, por outro lado, o avanço dos municípios cada vez mais próximos das aldeias, os indígenas começaram a perder muito de sua alimentação básica, que é a caça, passando a consumir os mesmos alimentos da população urbana, ocasionando, assim, um grave problema de diabetes e hipertensão na população acima de 30 anos de idade. Outros problemas detectados são: o alcoolismo, as drogas e até a prostituição.

Os acidentes com os indígenas, na BR 158, são constantes e, como exemplo, em algumas aldeias, como a de Areões e Pimentel Barbosa que ficam próximas aos municípios de Nova Xavantina e de Água Boa, os indígenas que andam nos pequenos acostamentos para as cidades sofrem atropelamentos e alguns, que possuem carros, e normalmente, estão em péssimas condições de manutenção, quando vão às cidades, em alguns casos, abusam do consumo de 
álcool e voltam dirigindo para as aldeias, provocando, graves acidentes, principalmente com as carretas, das quais não conseguem desviar, ou frear rapidamente (DEMAMBRO, 2017 p. 84).

\section{Considerações finais}

A história da construção da BR 158/MT se inicia nos idos de 1944 no Governo Getúlio Vargas com a recém-criada Fundação Brasil Central. Vargas tinha a intenção de fazer com que as estradas fossem os instrumentos de comunicação entre as regiões longínquas do Brasil.

A construção da parte terrosa da BR 158/MT teve seu término em 1980. O asfaltamento teve início em 1985 e o término em 2015, ou seja, são mais de 70 anos para esta rodovia ser o que é nos dias de hoje, ainda não computado o tempo que levará para se asfaltar o trecho que contorna as terras indígenas de Marãiwatsédé, mais $210 \mathrm{~km}$, o que representa um tempo maior no desenvolvimento da região.

Não há como negar que as transformações socioespaciais ocorridas na região Centro Oeste do Brasil, tem o Estado como o maior fomentador, e de maneira mais intensa o Estado de Mato Grosso, onde projetos de colonização e o avanço do agronegócio faziam com que indígenas assistissem seus territórios sendo invadidos e tendo grandes perdas de espaço, diminuindo e dificultando suas práticas tradicionais e culturais. Com a intenção de cumprir as metas do governo federal, o Estado de Mato Grosso priorizou o desenvolvimento econômico, assim grande parte de comunidades tradicionais como as populações indígenas sofreram fragmentações territoriais e principalmente os Xavantes de Marãiwatsédé, que praticamente foram desteritorializados.

Desde 1966 quando foram expulsos de Marãiwatsédé até seu retorno definitivo em 2013 o povo Xavantes sofreu com perdas significativas de sua população, seja por doenças ou violência, porém encontraram diferentes formas de se manterem no território e preservarem a essência de sua identidade. Nas entrevistas com os representantes das populações indígenas, foi observado que, como eles vivem em reservas já determinadas pelo governo federal, necessitam muito da BR 158. Mesmo não tendo participado das discussões preliminares da implantação dessa rodovia, acham que ela é extremamente necessária para eles, porque os aproximou das cidades onde encontram assistência à saúde e também têm acesso à educação.

A reclamação principal deles em relação a BR 158 é a falta de acostamento, devido ao fato de trafegarem muito pelos curtos espaços destinados ao acostamento e sofrerem muitos 
acidentes. Ficou explícito que, mesmo em reservas, os povos indígenas continuam sendo dizimados, não por armas, mas por doenças silenciosas que adquirem na intensa convivência nas regiões urbanizadas.

\section{Referências}

AXA, ARTICULAÇÃO XINGÚ ARAGUAIA. Posseiros retirados de Mariwatsede serão assentados em Santa Terezinha e Alto Boa Vista. 2014. Disponível em: https://axa.org.br/2014/02/posseiros-retirados-de-maraiwatsede-serao-assentados-em-santaterezinha-alto-boa-vista/. Acesso em 08/04/2019.

BRASIL. IBGE Cidades. Disponível em: https://cidades.ibge.gov.br/brasil/mt/panorama>. Acesso em: 10/02/2019.

CANUTO, Antonio. O árduo e longo caminho para o e conhecimento dos direitos de comunidades tradicionais Direitos Humanos no Brasil 2012 Relatório da Rede Social de Justiça e Direitos Humanos. In: MERLINO, Tatiana. MENDONÇA, Maria Luisa. Direitos Humanos no Brasil 2012: Relatório da Rede Social de Justiça e Direitos Humanos. Disponível em: http://reporterbrasil.org.br/documentos/DH relatorio 2012.pdf. Acesso em: 17/12/2019.

CASALDÁLIGA, P. Uma igreja na Amazônia em conflito com o latifúndio e a marginalização social. São Félix do Araguaia, 1971. Disponível em:

http://www.servicioskoinonia.org/Casaldaliga/cartas/1971CartaPastoral.pdf>. Acesso em: 25/09/2019.

DELUCl, Luciana A.S. \& PORTELA, Cristiane de Assis. Marãiwatsédé: Memória de Luta, Resistência e Conquista. XXVII Simpósio Nacional de História: ANPUH, RN, 2013.

DEMAMBRO, E. Eixo de integração viária: impactos econômicos e sociais da BR 158 sobre as cidades do Vale do Araguaia mato-grossense entre 2000 e 2014. Dissertação de mestrado. PUC Goiás. Goiânia, 2017.

DNIT. CONTRAN Limites legais. Disponível em:

http://www1.dnit.gov.br/Pesagem/qfv\%20pdf.pdf. Acesso em: 17/11/2015.

DNIT. Histórico do rodoviarísmo. Brasília. Disponível em: http://www1.dnit.gov.br/historico/. Acesso em: 18/01/2019.

FERRAZ \& MAMPIERI. [Artigo]. Suiá Missú: um mito refeito. IN: ISA - Instituto Socioambiental, Povos Indígenas no Brasil 1991/95. 1994. Disponível em:

<http://www.maraiwatsede.org.br/tags/documentos>. Acesso em 20/05/2014.

GARFIELD, Seth. A luta indígena no coração do Brasil. Politica Indigenista, a marcha para o Oeste e os índios Xavante (1937-1988). Trad. Claudia Sant'Ana Martins. São Paulo: Editora Unesp, 2011.

GALVÃO, J.A.C. "Colonização e cidades do Mato Grosso". XXVII Simpósio Nacional de História, Conhecimento histórico e diálogo social. artigo, Natal, 2013.

GIACCCARIA, B. ENSAIOS: Pedagogia Xavante-Aprofundamento Antropológico. Missão Salesiana de Mato Grosso. Campo Grande, 1990. 
GOLDENBERG, M. A arte de pesquisar: Como fazer pesquisa qualitativa em Ciências Sociais. Rio de Janeiro: Record, 1997.

GOMIDE, M. L, C. MARÃNÃ BÖDÖDI - a territorialidade Xavante nos caminhos do Ró. 2008. Tese (Doutorado em Geografia) - Departamento de Geografia, FFLCH/USP, São Paulo, 2008. HEIDEGGER, M. (1993). Ser e Tempo. Petrópolis: Vozes. (Originalmente publicado em 1927). OLIVEIRA, L. L. A Conquista do Oeste. Fundação Getúlio Vargas. CPDOC - Centro de Pesquisa e Documentação de História Contemporânea do Brasil, 2015. Disponível em: http://cpdoc.fgv.br/producao/dossies/JK/artigos/Brasilia/ConquistaOeste. Acesso em: 19/10/2016.

PÉREZ JÁUREGUI, M. I. El proyecto de vida laboral. 2016. Disponível em:

$<$ https://racimo.usal.edu.ar/4530/. Acesso em 10/04/2019.

POLLAK, Michael. Memória, esquecimento, silêncio. Revista Estudos Históricos, Brasil, v. 2, n. 3, p. 3-15, 1989.

REDE BRASIL ATUAL. Marãiwatsédé. Aqui viviam nossos ancestrais. 2014. Disponível em: <https://www.redebrasilatual.com.br/revistas/97/aqui-viviam-nossos-ancestrais-3809.html>. Acesso em: 13/03/2019.

ROCHA, L. Da terra onde se retira o pão também se constrói o território: as transformações socioterritoriais sofridas pelo Povo Xavante em decorrência do avanço do agronegócio na Terra Indígena Marãiwatsédé. Tese apresentada ao Programa de Pós-Graduação. Universidade Federal de Uberlândia. Uberlândia, 2018.

RODRIGUES, Patrícia de Mendonça. [Laudo]. Relatório de identificação da área indígena "Marãiwatsédé". Brasília: FUNAI, Portaria n. 9 de 20/01/1992.

ROSA, J. C. e TAFNER, A. W. Jr. A luta pela terra Marãiwatsédé por meio da biografia de Damião Paridzané. 2018. Disponível em: <https://osbrasisesuasmemorias.com.br/wpcontent/uploads/2018/04/Dami\%C3\%A3o-Paridzan\%C3\%A9.pdf>. Acesso em: 30/03/2019.

SR/DNIT/MT. Br 158/MT. Manual DNIT, 2015. Mato Grosso, Brasil. Disponível em: <http://www.dnit.gov.br/acesso-a-informacao/insitucional/copy_of_quem-equem/superintendencias-regionais-do-dnit-nos-estados/mato-grosso >. Acesso em: $17 / 07 / 2015$.

SUDECO. Superintendência do Desenvolvimento do Centro Oeste, 2016. Disponível em: http://www.sudeco.gov.br/web/guest/historico. Acesso em: 10/12/2019.

TAFNER Jr., A. W; SILVA, F, C. Expropriação de terras e exclusão social na Amazônia MatoGrossense. PRACS: Revista Eletrônica de Humanidades do Curso de Ciências Sociais da UNIFAP. Macapá, v. 8, n. 2, p. 87-117, jul./dez. 2015. Disponível em:

https://periodicos.unifap.br/index.php/pracs. Acesso em: 16/03/2019.

VALE DOS ESQUECIDOS. Documentário-longa Metragem. Direção: Maria Raduan. Fotografia: Sylvestre Campe, color, (72 min.): Tucura Filmes, Brasil, 2010. Disponível em: <http://valedosesquecidos.com.br/\#ficha-tecnica/maria-raduan>. Acesso em: 25/04/2012. WELCH, J.R et al. Na Primeira Margem do Rio: Território e Ecologia do Povo Xavante. Museu do Índio-funai, Rio de Janeiro, 2013. 